\title{
ASPECTOS NARRATIVOS DE LA IDENTIDAD PERSONAL
}

\section{Juan Ignacio Blanco Illari*}

Resumen: En este trabajo quisiera mostrar la necesidad de recurrir a una concepción narrativa de la identidad personal. Para ello, tomo las corrientes actuales de la identidad personal e intento señalar sus lagunas y debilidades. Dichas debilidades se deben al olvido de la dimensión narrativa en el tratamiento del problema. Primeramente, analizo la línea "descriptiva" de la identidad, toma el trabajo de Parfit e intento mostrar el contraste con los argumentos narrativistas de MacIntyre y Ricoeur. Luego repaso la teoría normativa en la versión elaborada por Tugendhat. Allí muestro de qué modo la identidad narrativa permite una mejor comprensión del problema. En efecto, la identidad personal parecería involucrar una mixtura de posesión y desposeimiento, acción y pasividad, que sólo la narración puede armonizar dando a la identidad unidad y completitud.

Palabras clave: identidad - personal - narratividad

Abstract: In this paper I will try to show the need to resort to a narrative conception of personal identity. In order to do so, I will take the most significant lines on personal identity and I will show their weaknesses and gaps. Such weaknesses are generated by the lack of narrative dimension. Firstly, I will analyze the "descriptive" line of the personal identity; I will take Parfit's work, and I will try to contrast with it the "narrativistic" arguments of MacIntyre and Ricoeur. Then I will turn to the normative theory, as it is elaborated by Tugendhat, in order to show how the narrative identity allows a better comprehension of the personal identity problem. In fact, the personal identity seems to involve a mixture of possession and dispossession, action and inaction, that only a narration can combine giving the identity unity and totality.

Key words: personal - identity - narrativity

* Doctor en Filosofía por la Universidad Nacional de La Plata. Becario Postdoctoral del CONICET Profesor de la Universidad Nacional de General Sarmiento y del Instituto Universitario ESEADE. Profesor Invitado de la Universidad Católica Argentina. Dirección electrónica: juan_blanco2001ar@hotmail.com. 


\section{Introducción}

Es difícil no reconocer la importancia que la identidad personal tiene, no sólo para las ciencias humanas en general, sino también para muchas otras disciplinas. Es un dato que hace a la complejidad y alcance de la cuestión el que la identidad personal sea abordada desde ángulos tan distantes: desde la filosofía hasta la genética, pasando por el derecho, la sociología, la psicología, la biología, etc.. Esta polifonía debería advertirnos desde el inicio que la búsqueda de una respuesta unívoca y definitiva no se corresponde con la naturaleza del problema. Tampoco deberíamos suponer que hay una pregunta rectora que reúne bajo su órbita el resto de las cuestiones que dispara el problema. Por ejemplo, tenemos de un lado los problemas jurídicos de la identidad, los juicios de filiación y, más recientemente, los juicios por la verdad, en los que se intenta develar la "identidad" de la persona. También tenemos la cuestión psicológica del "desarrollo de la personalidad", y de la construcción de la identidad del yo. Por otro lado, aparecen cuestiones relativas a la dimensión social (sociológica) de esa construcción, cuestiones biológicas que entran en juego, etc. La unidad entre estas líneas interrogativas debe buscarse más del lado de la metáfora wittgensteiniana de los "parecidos de familia" que de la metafísica platónica de la unidad de un eidos.

Desde hace ya varios años, la identidad narrativa, propuesta especialmente por Ricoeur, aunque presente en otros autores de fuste (Ortega y Gasset, Charles Taylor, MacIntyre, Arendt, por nombrar sólo algunos), se ha colocado en el centro del debate. Lo que me propongo demostrar es que la narratividad no es una prerrogativa que podamos agregar o no al análisis de la identidad personal. Por el contrario, la narración es "constitutiva" de la identidad, y en este sentido, forma parte esencial de ella.

La teoría narrativa de la identidad personal muestra su capacidad y completitud explicativa cuando se la confronta con las perspectivas descriptivo-reduccionista y práctico-normativa. Estas dos formas de análisis parecen excluirse mutuamente, sin embargo la identidad narrativa 
se presentará como puente entre ellas según el axioma de Ricoeur: "entre describir y prescribir, narrar"1.

\section{Las teorías descriptivas}

Dentro del complejo panorama que abre la cuestión de la identidad personal; hay un consenso más o menos establecido en cuanto a los dos meta-enfoques que gobiernan los diferentes análisis. De un lado se alzan las teorías que abordan a la identidad personal bajo el paraguas de una ontología descriptiva. Estas se han desarrollado, a su vez, conforme a dos modelos: el modelo reduccionista; y el modelo no-reduccionista. Realizaré un sobrevuelo de las tesis centrales de ambas teorías para contrastar la consistencia de la hipótesis.

\subsection{La tesis reduccionista}

La tesis reduccionista es la que proviene de Hume, Locke, y tiene como uno de sus últimos representantes a Derek Parfit. Según este autor, si la identidad personal es un tipo de identidad, lo más recomendable es comenzar por analizar la noción de la "identidad". Así, podemos distinguir la identidad numérica de la identidad cualitativa:

dos bolas de billar no son númericamente pero sí cualitativamente idénticas. Si pinto de rojo una de estas bolas, no será entonces cualitativamente idéntica a sí misma tal cómo era ayer. Pero la bola roja que veo ahora y la bola blanca que pinté de rojo son numéricamente idénticas. No son sino una y la misma bola...2

Si aplicamos prima facie esta distinción a la persona, entonces podríamos decir que no hay contradicción a priori en decir que una persona, después de algún hecho relevante en su vida, es numéricamente la misma, pero cualitativamente otra. Según esta forma de hablar, la

${ }^{1}$ Cfr. Ricoeur P., Si mismo como otro, México, Siglo XXI, 1996, p. 108.

2 Parfit, D., Reasons and Persons, New York, Oxford University Press, 1986, p. 201. 
persona es y no es la misma, siempre y cuando tengamos presente los diferentes usos de la palabra "misma". Si Juan ha cambiado radicalmente después de su accidente, entonces solemos decir que "es una nueva persona", "que ha nacido de nuevo", aunque sepamos que numéricamente se trata del mismo individuo. Parfit refiere el caso de Cassius Marcellus Clay quien, luego de su conversión mística, se transformó en otra persona: Muhammad Ali. Desde luego se trata de una conversión cualitativa, no numérica, pues si fuera numérica ya no podríamos decir qué/quién cambió.

En vista de esta posibilidad, Parfit señala tres preguntas fundamentales sobre la cuestión de la identidad, tres preguntas que se resumen en una cuarta: “(4) ¿Qué está implícito de hecho en la continuidad de una persona a lo largo del tiempo?" 3 . De esta manera se ve claramente que lo que está en juego es el problema de la continuidad de la misma persona a través del tiempo. Siempre el modo de preguntar señala los presupuestos no declarados de una teoría. Aquí, Parfit sale a la caza de un becho, empiricamente constatable, en el que consista la identidad personal en su relación con la temporalidad.

En una primera aproximación podríamos decir que la tesis reduccionista implica dos presupuestos fuertes:

(1) que el hecho de la identidad de una persona a través del tiempo consiste sólo en la posesión de ciertos hechos más particulares, y (2) que estos hechos pueden ser descritos sin presuponer la identidad de esa persona, sin afirmar explícitamente que esa persona tiene tales experiencias en su vida e incluso sin afirmar explícitamente que esa persona existe. Esos hechos pueden ser descritos de manera impersonal ${ }^{4}$.

Una ontología de los hechos no puede sino administrar una metodología objetivista, en la que la primacía la tiene la "tercera persona" por sobre la perspectiva de la primera. Que los hechos en los que consiste

${ }^{3}$ Ibidem, p. 202.

${ }^{4}$ Ibidem, p. 210. 
la identidad personal puedan describirse de modo impersonal, significa que no necesitan armonizar con la perspectiva yoica. Así, tratamos a la persona como un objeto de conocimiento que, en principio, no presenta diferencias relevantes con otros objetos. $\mathrm{Si}$ algo es un ente, tiene que tener identidad.

El criterio principal, que nos permite distinguir cuándo un individuo tiene la identidad requerida, es el de la "continuidad". Según este criterio (a) un sujeto $\mathrm{X}$ en un tiempo t.1 es idéntico a un sujeto $\mathrm{Y}$ en t.2 si se puede establecer una continuidad ininterrumpida entre los hechos psicológicos y neurofisiológicos de $\mathrm{X}$ e $\mathrm{Y}$, pero este criterio, aunque necesario, es insuficiente, porque, (b) la continuidad exige que la conexión sea de un determinado tipo. Podemos decir, que los hechos de $\mathrm{X}$ e $\mathrm{Y}$ se superponen, $o$ se implican, $O$ se relacionan causalmente, $o$ teleológicamente, o sistémicamente, etc.

Al aplicar este criterio Parfit intentará derribar tres creencias ordinarias con respecto a la identidad: (1) la primera concierne a lo que debemos entender por identidad personal, esto es, la existencia separada de un núcleo de permanencia; (2) la creencia de que puede darse siempre una respuesta absoluta sobre la existencia de semejante núcleo de permanencia; y (3) la creencia según la cual, la identidad personal es un requisito importante para que la persona pueda constituirse en sujeto moral. Veamos como procede Parfit para derribar en bloque estas creencias.

Sobre (1): En sus análisis Parfit parece tener como tesis rival la teoría egológica de ascendencia cartesiana. Para no caer en los calambres conceptuales que supone la doctrina del "fantasma en la máquina", es necesario mostrar que la identidad personal se reduce al hecho (o no) de cierto encadenamiento entre acontecimientos psíquicos $o$ neurofisiológicos. Fuera de este encadenamiento no hay nada. Lo que excluye la tesis reduccionistas es, precisamente, que seamos entidades separadas. En términos de Parfit, aparte de esta conexión no hay ningún "Hecho Ulterior", llámese res-cogitans, yo trascendental, en que consiste la identidad personal. Ahora bien, la teoría reduccionista parte de la siguiente definición: "La existencia de una persona consiste simplemente 
en la existencia de un cerebro y un cuerpo, y en el acontecimiento de una serie de eventos físicos y mentales interrelacionados"5.

Lo que esta definición supera es, según Parfit, el subjetivismo de la tesis contraria (cartesiana). Si, como supone la tesis no reduccionista, la identidad personal se atiene a un hecho subjetivo central (como puede ser el caso del yo pienso que debe poder acompañar a todas mis representaciones), entonces esta tesis se enfrenta con un problema insuperable: este hecho no seria accesible, ni por ende corregible, desde la perspectiva de la tercera persona. Pero, agrega Parfit, no es contradictorio pensar en la posibilidad de que estemos equivocados con respecto a nosotros mismos. Podríamos suponer que, aunque yo recuerde haber estado en la histórica final de fútbol del Mundial 86, en realidad yo no estuve allí. Esto sería posible si se lograse trasplantar, de un cerebro a otro, la zona que almacena la memoria. Es sólo una cuestión de tiempo para que la ciencia haga posible técnicamente este trasplante. Así, si a mí se me injertara la memoria de Pedro, entonces, si Pedro estuvo en aquella final, yo recordaré, desde la perspectiva yoica, haber estado en ese partido. Pero esto no sería verdad. Es decir, no sería verdad que yo estuve en ese partido, aunque sea verdad que yo recuerdo haber estado en ese partido.

La estrategia de Parfit para evitar este subjetivismo, con sus consecuencias paradójicas, es poner a la identidad personal como un mero asunto de "hechos/acontecimientos" objetivos (sean psíquicos o físicos). La base de la estrategia consiste en "despersonalizar" los hechos o acontecimientos psíquicos, es decir, dar de ellos una descripción en tercera persona, que no requiera la adscripción a una sustancia yoica. De ahí la tendencia de Parfit a hablar de huella cerebral o mnémica.

$\mathrm{Si}$ podemos intercambiar experiencias de un sujeto a otro, la "posesión" de estas experiencias no es necesaria. Además, quedaría demostrado que no tenemos ninguna evidencia empírica para afirmar que, al lado de la experiencia, hay un "sujeto-yo" poseedor de dicha experiencia. Lo que hay son "experiencias" que se conjugan de determinada manera. Si hubiera que adscribir la experiencia a "algo" 
deberíamos adscribírsela al cuerpo. Parfit suscribe plenamente la observación que Lichtenberg le hiciera a Descartes: cuando este llegó al cogito, debió haber dicho "hay el pensar de un pensamiento" en lugar de "yo pienso". La primera formulación no adelanta ni presupone ningún sujeto-yoico de posesión. Si se hubiera atenido a lo que de hecho estaba sucediendo nos hubiese ahorrado muchos quebraderos de cabeza.

Sobre (2): Una vez eliminada la tesis del "hecho ulterior", el presupuesto de la decidibilidad sobre tal hecho cae por sí sólo. Es aquí donde se hace pesar el recurso a los puzzling cases. La estrategia ahora consistirá en buscar ejemplos en los que la identidad, tal como la entiende la further theory (egología), queda refutada merced a la imposibilidad de resolver la cuestión de la continuidad de la identidad por sí o por no ${ }^{6}$. Entonces: "Si aceptamos la Perspectiva Reduccionista, puede haber casos en los que creamos que la identidad de una cosa es (...) indeterminada. No creeríamos esto si rechazaramos la Perspectiva Reduccionista sobre este tipo de cosas..."7.

Parfit propone el siguiente ejemplo: supongamos que un club que ha existido durante algunos años, con encuentros regulares y regulados

${ }^{6}$ Hay que reconocer la sagacidad e inventiva de Parfit al momento de presentar los "casos" imaginarios. Quizá el más conocido y resonante sea el de la "teletrasportación" que presentaré de manera abreviada: supongamos que, para viajar a Marte yo tengo dos métodos. Uno es el viaje común (en nave espacial) y el otro es por medio de la teletrasportación. Mediante esta segunda modalidad, ingreso en una cápsula que mediante un scanner graba toda la información contenida en cada una de mis moléculas, luego destruye mi materia orgánica, envía la información a destino por radio y reproduce, a partir de materia orgánica, una a una mis moléculas. Yo pierdo unos segundos la conciencia y la recupero en Marte. A partir de aquí Parfit dispara sus preguntas. ¿Soy yo el que se despierta, o es alguien idéntico a mí? Lo que quiere demostrar es que la respuesta a esta pregunta es una cuestión de decisión discrecional, que no hay nada en los hechos que me permita resolver la cuestión. Esto no quiere decir que haya algo que se me escapa en mi descripción de lo que sucede. Yo sé todo lo que va a pasar y aún así no puedo contestar por sí o por no a la pregunta por la identidad (¿será que esta pregunta no se resuelve describiendo los hechos?).

${ }^{7}$ Ibidem, p. 213. 
claramente, se cierra. Algunos años más tarde algunos miembros de este club deciden reabrirlo con el mismo nombre, las mismas reglas y la misma programación de encuentros. La pregunta sería: ¿es éste el mismo club?, ¿o simplemente se trata de abrir otro club idéntico al anterior? Según la tesis no-reduccionista deberíamos poder dar una respuesta concluyente a esta cuestión, porque debería haber un hecho específico, constatable, cuya presencia o ausencia me permita decidir por sí o por no la cuestión de la identidad. La respuesta a la pregunta chay identidad? tendría la misma lógica que la respuesta a la pregunta ¿hay o no hay angina? En ambos casos se trata de contrastar la existencia o no de un hecho. Sin embargo, Parfit intenta demostrar que esto no es posible en el caso de la identidad del club. En efecto, el club original podría haber previsto reglas explícitas sobre cómo, después de cerrarse por algunos años, debe ser reabierto para continuar siendo el mismo. Sin embargo esta regla "continuista" puede no estar, inclusive puede ocurrir que, si le preguntamos a los miembros del club, ellos tampoco puedan responder con claridad por sí o por no. De esta manera podríamos aventurar que "la afirmación 'Éste es el mismo club" no sería ni verdadera ni falsa"s.

¿Qué es lo que el ejemplo pretende demostrar? Que aunque la pregunta ¿es el mismo club? no pueda recibir una respuesta única, quizá no baya nada que nosotros no conozcamos sobre el club. Así, tal vez, la existencia continua del club consista en la existencia de los miembros y sus reuniones, y no haya ningún hecho, aparte de estos hechos, en el que consiste la identidad. Si nosotros supiéramos todos los hechos sobre cómo las personas realizan sus reuniones de acuerdo con las reglas claras del club, quizá sabríamos todo lo que hay que saber. De todas maneras, la pregunta ¿es el mismo club? puede seguir siendo susceptible de dos respuestas: sí y no. Parfit asegura que, aunque la respuesta sea indeterminada, eso no implica que la indeterminación se derive de que desconocemos algo importante sobre el club que nos permitiría una respuesta determinada. 
En esta situación, aunque no haya respuesta, nosotros podemos decidir darle una. Sin embargo, afirma Parfit, "nosotros podemos decidir considerar que el segundo club es el mismo que el primero. $\mathrm{O}$ podemos decidir considerarlo otro club que es exactamente igual" 9 . En este caso debemos aceptar que nuestra decisión no se basa en ningún dato objetivo. No hay nada en función de lo cual nosotros podamos fundamentar nuestra decisión. Nadie diría que, ante la pregunta de si " $x$ " es o no una molécula de agua, nuestra respuesta es meramente una decisión. Todos estaríamos de acuerdo en que, para que algo sea una molécula de agua tiene que tener dos átomos de hidrógeno y uno de oxígeno. Es por ello que la identidad de una molécula de agua es decidible en función de los hechos, mientras que la identidad de una persona no.

Sobre (3): Este último punto pareciera ubicarse del lado de las teorías prescriptivas, sin embargo Parfit la presenta como una consecuencia de su teoría descriptiva-reduccionista. Parfit intenta derribar el juicio de importancia que damos a la identidad personal combatiendo la teoría utilitarista de la moral llamada Self-interest theory. Muchos autores creen que la existencia de derechos y garantías se debe a la existencia de la identidad personal, que somos responsables de nuestras acciones en la medida en que somos agentes yoicos que no pueden reducirse a los hechos (sean físicos o psíquicos). Incluso la preocupación por nuestra vida y nuestra felicidad implica la preocupación por nosotros mismos en tanto somos personas, yoes que deben anticipar su futuro para tener un bienestar ${ }^{10}$.

Ahora bien, Parfit nos confronta con una cuestión anterior a la cuestión moral. Según él, toda nuestra vida práctica debería estar basada en nuestras creencias acerca de la ontología de identidad personal. Así, si yo creo que dentro de 50 años ya no existiré, no tiene demasiado sentido que haga promesas a cumplirse dentro de 52 años. Cualquier elección ética sólo tendrá razones de peso cuando logre disolver las falsas creencias sobre el estatuto ontológico de las personas. Así, cuando esto suceda (es decir, una vez aceptados los argumentos anteriores de Parfit), las cuestiones éticas

\footnotetext{
9 Ibidem, p. 214.

${ }^{10}$ Es el caso, por ejemplo, de John Rawls.
} 
fundamentales, v.g., la solidaridad, la universalidad, etc. podrán ser verdaderamente practicadas. Lo que la tesis reduccionista implica para la práctica es un total desinterés por sí mismo. Este desinterés representa la inmejorable ocasión de descentrarme como sujeto para poner el interés sobre los otros antes que sobre mí. Lo que busca Parfit es que nos interesemos más por las experiencias que por sus portadores, de esta manera, observa Ricoeur, opone la "despreocupación" (lo mismo que Jesús en el sermón de la montaña) al "cuidado".

Estos son, brevemente expuestos, los pilares sobre los que se levanta la variable más influyente de la tesis reduccionista.

\subsection{La tesis no-reduccionista}

Antes de continuar debemos tener presente que la tesis rival, que llamamos tesis no-reduccionista, puede subdividirse en dos: una de corte "ingenuo" (la heredada de la tradición cartesiana, y fuertemente desacreditada por buena parte de la filosofía contemporánea, entre ellos Parfit), y otra "no-ingenua", establecida por los defensores de la identidad narrativa. Sobre ella me centraré ahora. Veamos de qué manera la teoría narrativa de la identidad permite una mejor comprensión del fenómeno vía refutación de la tesis reduccionista more Parfit.

MacIntyre afirma que la condición de posibilidad de la comprensión de un concepto depende de las condiciones de posibilidad de aplicar con sentido dicho concepto (podríamos llamar a esto "estrategia wittgensteiniana"). De esta manera, MacIntyre elabora tres condiciones de aplicabilidad del concepto de identidad personal.

a) Puesto que mi cuerpo no es algo que yo tengo (y que, quizá, pueda dejar de tener) sino algo que yo soy, parte de ser una y la misma persona a lo largo de la vida implica tener uno y el mismo cuerpo. Esta primera condición, si bien no está lo suficientemente desarrollada, le permite a MacIntyre desechar todos los experimentos de teletransportación y análogos. 
b) Yo, en tanto miembro de más de una comunidad, me ocupo en relaciones con otros las cuales duran a través del tiempo. Y puesto que yo, como miembro de estas comunidades, emprendo proyectos que se prolongan en el tiempo, debe ser posible, a lo largo de esta vida personal, atribuir una continua responsabilidad en estos proyectos. De esta continua responsabilidad se desprende la unidad de mi identidad.

c) Puesto que mi vida ha de comprenderse como un todo orientado teleológicamente, cuyo bien he de buscar en todo momento, mi vida ha de tener la unidad y continuidad de esa búsqueda cuyo correlato es el bien de la vida como un todo. La unidad, entonces, de la identidad personal, es la unidad de mi historia, una historia con principio, nudo y desenlace. Aqui aparece la condición narrativa de la identidad persona ${ }^{11}$.

Estos tres aspectos, según señala MacIntyre, tienen una relación de interdependencia, y concurren al momento de aplicar el concepto de identidad personal. Sobre esta base, hay que señalar que:

1) No es una explicación que provenga del vocabulario técnicofilosófico, sino que, esta forma de entender la identidad y continuidad personal se enraíza en una precomprensión presente en el hombre mucho antes de la teoría filosófica ${ }^{12}$.

2) Aunque atribuye unidad a la vida humana, reconoce un elemento de contingencia ineludible: la existencia ininterrumpida del cuerpo, la continuidad y fiabilidad de la memoria, la relativa estabilidad de ciertos rasgos del carácter, etc.

3) Esta concepción de la identidad personal no se propone como solución a lo que se ha llamado "problema de la identidad personal" desde Locke, Butler, Flew o el mismo Parfit. El

11 Cfr. MacIntyre, A., Tres versiones rivales de la ética, Madrid, Rialp, 1992, pp. 244246. 
problema sólo aparece cuando las creencias compartidas (a, b y c) ya no se mantienen. Ahora bien, cuando esto sucede, el concepto de "la misma persona" plantea un problema con soluciones rivales. En ausencia de un marco conceptual común, las propuestas rivales son equipotentes, y, por ello, igualmente válidas.

Ahora bien, las tres condiciones, junto con los tres corolarios, constituyen el armazón del argumento de MacIntyre. Si pensamos en universos en donde las condiciones de aplicabilidad ya no pueden ser tenidas en cuenta (por ejemplo en el caso que consigné en la nota 6), entonces el concepto se hace ininteligible o al menos incomprensible. Suponer que la respuesta a la pregunta ¿qué tipos de juicios sobre la identidad personal haríamos en tales mundos imaginarios? arrojaría luz sobre la forma que tenemos de comprender dicho concepto en este mundo real, es una suposición infundada, pues la misma pregunta es una pregunta sin respuesta posible. Para poder dar respuesta a tal pregunta es conditio sine qua non ser habitante de dicho mundo.

Así, cuando Quine advirtió que "buscar lo que se requiere lógicamente para la mismidad de la persona bajo condiciones sin precedentes equivale a suponer que las palabras tienen cierta fuerza más allá de lo que nuestras necesidades pasadas les han otorgado"; Parfit pudo responder que "estos casos (los puzzling cases) despiertan en la mayoría de nosotros arraigadas creencias. $Y$ se trata de creencias, no sobre nuestras palabras sino sobre nosotros mismos". A esto sólo se puede contestar, a su vez, que la apelación a la mayoría de "nosotros" depende, respecto a su fuerza, de quiénes seamos nosotros ${ }^{13}$.

Entonces, siguiendo a Quine, MacIntyre puede afirmar que, analizar la cuestión de la identidad personal apelando a ejemplos como "teletransportación" o "clubes" implica trasladar la problemática a regiones en las cuales el concepto se aplica de otra manera. En última instancia se trata de una variante de petitio principii, ya que realizar esta

13 Ibidem, p. 247. 
homologación entre "personas" y "cosas", no sólo hace superfluos algunos argumentos, sino que también presupone algo que hay que demostrar.

La estrategia de Ricoeur no es tan radical. El primer argumento adquiere un tono fenomenológico; el segundo, hermenéutico. Será este último argumento el que nos permitirá tender un lazo con el de Arendt. Para ello debemos recordar, aunque sea brevemente, la distinción que realiza Ricoeur entre dos modelos de identidad, la identidad-idem, y la identidad-ipse. Ambas se presentan como dos modelos de identidad merced a la peculiar relación que cada una de ellas tiene con la temporalidad. Así, a la identidad-idem le corresponderá el "carácter" como modo de permanencia, mientras que a la identidad-ipse le corresponderá la "promesa" como modo de mantenimiento del sí. La importancia de la diferencia se percibe mejor si tenemos en cuenta las connotaciones temporales que implican las palabras "permanencia" y "mantenimiento". La tesis de Ricoeur es que la identidad personal es una dialéctica entre idem e ipse $e^{14}$. Y esa dialéctica se manifiesta en el movimiento de la narración. De allí que la identidad personal (en tanto dialéctica idem-ipse) sea identidad narrativa.

Pasemos ahora a los argumentos en contra de la tesis reduccionista de Parfit. El primero pone en tela de juicio la validez del concepto de "acontecimiento" (o hecho) como vértice de la explicación de la identidad personal. Lo que la tesis reduccionista reduce, casi aproblemáticamente, es lo que no puede ser reducido so pena de caer en una concepción demasiado abstracta de la identidad personal. El termino acontecimiento, tal como lo usa Parfit, opera una importante elisión de la "calidad de mío" tanto de "micuerpo" como de "mi-vivencia". No bay posibilidad, afirma Ricoeur, de bacer derivar la cualidad fenomenológica de la posesión de una ontología del acontecimiento impersonal. Entonces, lo que supuestamente gana Parfit en objetividad lo pierde nuevamente en aplicabilidad; esto siempre y cuando supongamos que la identidad personal es la identidad de "alguien". La cuestión estriba

14 Para un análisis más detallado de esta distinción, cfr. Ricoeur, P., Sí mismo como otro, pp. 106-137. 
en si es posible desentenderse de la posesión por parte de alguien de su cuerpo y sus estados psíquicos. El acontecimiento mental (huella cerebral, mapa neuronal) señala la neutralización del cuerpo propio. Así, la verdadera diferencia entre la tesis reduccionista y la no-reduccionista no está tanto en la cuestión del dualismo de las sustancias, sino entre " $m i$ pertenencia y la descripción impersonal'. Para concentrarse en la noción de "cerebro" la tesis reduccionista debe, primero, reducir el cuerpo propio a un cuerpo cualquiera. Así se pasa de la intuición "yo-pienso" al oxímoron "el cerebro piensa"15.

Ahora bien, la importancia que tiene para Ricoeur la ficción en la constitución de la identidad narrativa hace que el recurso a los puzzling cases (que podríamos caracterizar como de "ciencia-ficción") no sea rechazado en bloque como lo fue en MacIntyre. Lo que este tipo de casos demuestran, según los análisis de Parfit, es lo que podríamos denominar "ilusión de la condición de decidibilidad de la identidad personal".

Es aquí donde el contra-argumento fenomenológico elaborado por Ricoeur encaja con el contra- argumento hermenéutico. Tansformando a la identidad en una cuestión de supervivencia, los puzzling cases disocian lo que en la vida cotidiana consideramos indisociable (este argumento tiene un "aire de familia" con el de MacIntyre) y cuyo nexo experimentamos como nocontingente: la relación entre la conexión psicológica y corporal (que puede incumbir más o menos a una descripción impersonal), y el sentimiento de pertenencia (en especial de los recuerdos, afirma Ricoeur) a alguien capaz, de autodesignarse como su poseedor. Es claro que, si bien

15 “Combatiré (...) una amalgama semántica, y que veo resumida en la fórmula, digna de un oxímoron: 'el cerebro piensa' (...). Lo mental vivido implica lo corporal, pero en un sentido del término cuerpo irreductible al cuerpo objetivo tal como se conoce en las ciencias objetivas. Al cuerpo objeto se opone semánticamente, el cuerpo vivido, el cuerpo propio (...). Así, pues, el cuerpo figura dos veces en el discurso, como cuerpo-objeto y como cuerpo-sujeto, o mejor, como cuerpo-propio" (Ricoeur, P. y Changeux, J-P. Lo que nos hace pensar, Barcelona, Península, 1999, p. 22). De esta manera, si la identidad personal implica una forma de comprenderse a sí mismo del sujeto, entonces, se coloca del lado del discurso fenomenológico más que del lado de las neurociencias. 
puedo estar equivocado en cuanto a la verdad de mi recuerdo (en realidad fue Pedro el que estuvo en aquella final, no yo), eso nada dice sobre el sujeto que recuerda. La situación sería la siguiente: yo recuerdo que yo estuve en la final del Mundial 86; puede ser una posibilidad que yo no haya estado en dicha final; pero, ¿qué sucede con el sujeto que recuerda?, ¿puede ser que no sea yo el que recuerda? La incorregibilidad de la primera persona no está en el contenido noemático, sino en el acto noético.

Finalmente, existe un elemento, aparentemente contingente de la condición humana que no puede ser obliterado por ningún puzzling case: la bistoricidad de la persona teletransportada. Aquí aparece el aspecto narrativo de la identidad personal que Parfit pareciera haber dejado de lado ${ }^{16}$. El viajero tiene una historia, y en esa historia aparecen sus miedos, deseos, incertidumbres, etc. Esa historia es también la que lo une de una manera intransferible a su cuerpo. La tesis de Ricoeur es que la unidad de la persona es subsidiaria de la unidad de su historia. La identidad personal es subsidiaria de la narración, pues es el carácter unitario y completo de la historia narrada lo que otorga unidad y completitud al personaje ${ }^{17}$. Entonces, la unidad del viajero es la unidad de una narración.

Mientras se considere sólo la adecuación de la réplica al cerebro reduplicado, sólo cuenta la identidad de estructura, comparable a la del código genético, preservado a lo largo de toda la experiencia. En cuanto a mí que soy teletransportado, me sucede continuamente algo: temo, creo, dudo, me pregunto si voy a morir o sobrevivir, en una

${ }^{16}$ ¿No se refiere Nagel a este aspecto "histórico" cuando señala que "si se produjera una réplica de mi físicamente distinta, que tuviera continuidad psicológica conmigo, aunque mi cerebro hubiera sido destruido, tal réplica no sería yo, y su sobrevivencia no sería tan buena (para mí) como mi sobrelivencia?" (Nagel, T., Una visión desde ningún lugar. México, F.C.E, 1996, p. 67. Subrayado nuestro).

17 "En efecto, en la historia contada, debido al carácter unitario y completo que le confiere la operación de elaborar la trama, el personaje conserva, a lo largo de la historia, la identidad correlativa a la de la propia historia" (Ricoeur, P., Historia y Narratividad, Barcelona, Paidós, 1999, p. 218). 
palabra, me preocupo. En este aspecto, el deslizamiento de la cuestión de los problemas de memoria a los problemas de supervivencia señala la aparición de una dimensión de historicidad cuya descripción impersonal parece muy difícil de hacer ${ }^{18}$.

Con la bistoricidad bace su aparición la narratividad en tanto forma de recobrar dicha bistoria. Si existe la posibilidad de que alguien narre los avatares de los desdichados viajeros, entonces, la cuestión de la decidibilidad sigue siendo, aunque frágil, posible. Para encontrar la identidad de cada uno de ellos, basta narrar lo que a cada uno le ocurrio. La unidad del viajante es la unidad del relato de su propia historia. Sin embargo, ¿no es la narración una decisión?, ¿no sigue siendo la identidad algo convencional? No, porque en esta narración hay pretensión de verdad: constitución y descripción se dan al mismo tiempo.

Hannah Arendt desarrolla un enfoque similar. La unidad buscada, esto es, la unidad de la identidad, no es una cuestión de conexiones psicofisiológicas, sino más bien es una unidad derivada del/los relato/s. Es el movimiento narrativo el que permite ligar los diferentes momentos de la persona, a punto tal que la noción misma de persona pareciera ser la de "personaje" extraído de su historia. No hay identidad hasta que no haya un relato significativo para el sujeto portador de dicha identidad ${ }^{19}$. El error consiste, entonces, en buscar la unidad alli donde no puede aparecer, y de aqui concluir que no hay unidad. Si no podemos encontrar una identidad personal que haga posible contar una historia, entonces contemos una historia que haga posible la aparición del personaje y su identidad.

Finalmente, el argumento de Ricoeur sobre el tercer punto elaborado por Parfit. Lo que le señala es que la conclusión moral a la que llega provoca una crisis interna a la identidad. Volviendo a la cualidad fenomenológico-hermenéutica de la posesión de mis experiencias a mi

17 Ricoeur, P., Sí mismo como otro, p. 134.

${ }^{19} \mathrm{Cfr}$, también el análisis que sobre este punto realiza Leibovici, en: Leibovici, M., Hannah Arendt, une Juive: Expérience, politique et histoire, Paris, Desclée de Brouwer, 1998, pp. 32-69. 
mismo, Ricoeur marca el costado positivo de los puzzling cases de Parfit. Pues, lo que la identidad personal supone (como veremos más adelante) es, en realidad, una mezcla de posesión y desposeimiento. Aunque, "[s]i mi identidad perdiese toda importancia por todos los conceptos, ¿no se volvería también la del otro 'sin importancia'?"20.

La mezcla de posesión y desposeimiento hace emerger en el marco de la identidad personal la posibilidad de que, lo que yo sea, sea inconmensurable con lo que yo sé de mí mismo. Pero esta intuición abre una de las preguntas cuya respuesta se propone develar la identidad narrativa, a saber, ¿quién soy yo en verdad? La respuesta a esta pregunta se lleva a cabo en el registro de las denominadas tesis "normativoprescriptivas".

\section{Las teorías prescriptivas}

Algunos autores (v.g. Doménech) plantean una separación irreconciliable entre la perspectiva descriptiva y la prescriptivonormativa ${ }^{21}$. La diferencia pareciera ser, en efecto, esencial. En palabras de Tugendhat, la perspectiva descriptiva tiene como preocupación de fondo la "identidad numérica" de una cosa (sea un objeto o una persona). Se trata, entonces, de encontrar el operador identificante que me permita afirmar si un sujeto $\mathrm{X}$ en un tiempo t.1 es idéntico al sujeto $\mathrm{Y}$ en t.2. En este caso, se trata del mismo sujeto, numéricamente bablando. La pregunta que, según este autor, guía a las teorías descriptivas es: “¿Cómo puedo yo ser el mismo que hace veinte años, siendo ahora tan distinto que entonces?" 22

Lo que este modo de preguntar confunde es la ecuación "noidentidad y cambio". Si Tugendhat no ve ningún problema en la determinación de la identidad numérica, es porque no ha tenido

20 Ricoeur, P., Símismo como otro, p. 137.

21 Cfr. Aramayo, R., Muguerza, J. y Valdecantos, A. (comp.), El individuo y la bistoria, Barcelona, Paidós, 1995, pp. 29-42.

22 Tugendhat, E., Problemas, Barcelona. Gedisa. 2002, p. 18. 
suficientemente en cuenta la posibilidad de que algunos cambios alteren en forma profunda la respuesta a la pregunta ¿quién? Así, al no mencionar la variable narrativa de la identidad personal, no ha podido conjugar cambio y permanencia en el seno de un ser cuya temporalidad puede producir características irrecusables al momento de preguntar por la identidad.

En realidad se trata de conjugar dos intuiciones en principio antitéticas: por un lado es claro que yo soy el mismo que hace veinte años se encontraba en tal lugar, realizando tales actividades, con tales deseos y expectativas, etc.. Por otro lado es igualmente claro que yo ya no soy el mismo de hace veinte años, no en el sentido de que mi cuerpo ha cambiado en sus aspectos accidentales, sino que algunos cambios han sido relevantes para la comprensión que tengo de mi mismo. En este contexto, tiene sentido decir que, por determinadas causas o motivos, soy sustancialmente otro que hace veinte años.

Para las teorias descriptivas, la identidad personal es del orden del dato, es algo que está allí (o no) y que nosotros debemos contemplar. Las teorías prescriptivas, en cambio, ponen a la identidad en otro registro que el del dato. Lo que la identidad sea, es algo que tenemos que "hacer" más que descubrir. La identidad es una categoría de la práctica porque en realidad no está ahí para ser observada, sino que se plantea como una tarea. Si en las teorías descriptivas (exceptuando la variable narrativa) el sujeto portador de identidad parecía ser pasivo con respecto a ella, en las teorías prescriptivas, el sujeto se erige como mayormente activo. En una la identidad es algo "que me pasa", en la otra es algo que "tengo que hacer". Nuestra hipótesis emerge nuevamente: la única teoría que logra una correcta comprensión de la mezcla entre pasividad y actividad en la constitución de la identidad personal, es la identidad narrativa.

Centremos nuestro análisis en el autor ya citado. Tugendhat distingue dos tipos de preguntas por la identidad: la pregunta por aquello que hace que pueda reconocer este libro, que ahora está sobre la cama, como el mismo que ayer estaba en la biblioteca, y que hace unos días estaba en la librería; es la pregunta por la "identidad numérica". La "identidad cualitativa", en cambio, adopta la estructura del "identificarse- 
con". En la obra de Freud, por tomar un ejemplo destacado, la palabra "identidad" aparece muy pocas veces, y cuando lo hace, lo hace bajo la figura de la identificación con el pueblo judío. Aquí tenemos, según Tugendhat, una forma clásica de identificación cualitativa. Identificarsecon... no es algo que simplemente sucede, es algo que tenemos que hacer.

Es la identidad cualitativa la que representa los problemas más interesantes para el filósofo; es más, la identidad cualitativa se presenta como el problema fundamental de nuestras vidas. Este tipo de identidad, bajo la estructura del identificarse-con..., muestra la forma que tiene uno de auto-comprenderse. La pregunta fundamental de la identidad implica la respuesta a la cuestión de ¿quién quiere uno ser?, siempre y cuando entendamos esta pregunta como ¿qué y cómo quiero ser? Ahora bien, estas preguntas parecieran hacer referencia a la totalidad de mi existencia. Por ello, la identidad cualitativa no se refiere a datos objetivos (sexo, estatura, cerebro o mapa genético) como era el caso de la tesis descriptivoreduccionista, sino por el contrario, a cualidades subjetivas que tienen como horizonte el futuro, no al futuro inmediato, sino al futuro en su totalidad. Ser judío, en el caso de Freud, no era algo que podía agotar en una o algunas acciones, sino que era una cualidad que atravesaba toda su vida. No se sentía judío en el consultorio, y no judío con sus amigos. Resumiendo, la identidad cualitativa tiene como objeto de deliberación la cuestión del sentido de mi vida, entendiendo a ésta como un todo.

Pero la cuestión se torna un poco más compleja. La respuesta a la pregunta práctica fundamental parece depender y no-depender de nosotros. Aquí aparece, según Tugendhat, el orden del dato, pues "[t]odo lo que queremos ser por una parte ya está determinado, es algo dado; y, por otra, depende de nosotros mismos" 23 .

Si volvemos al ejemplo del padre de psicoanálisis esto se ve con claridad. Por un lado, Freud ya era judío, es decir, había nacido en el seno de una familia judía, pero por otro lado, él "elige" serlo, si entendemos esto en el sentido de una reapropiación voluntaria, tal como debiéramos entenderlo si la colocamos bajo la estructura "identificarse-con...". Por lo

${ }^{23}$ Ibidem, p. 20. 
tanto, la identidad cualitativa implica, por un lado, que podamos reconocer lo que "ya somos", y por otro, que podamos hacer algo con ese reconocimiento, esto es, aceptarlo libremente, o libremente negarlo. En el caso en que se acepte, el dato formará parte constitutiva de mi identidad, y en el caso de negarlo, el dato sólo podrá eventualmente formar parte de las características objetivas (el "hecho" de nacer dentro de la comunidad judía), pero no será parte de la identidad cualitativa del sujeto toda vez que no aparece como una manera relevante de autocomprenderse. Se trata, en términos de Tugendhat, de la diferencia entre el comportamiento teórico consigo mismo (cuyo horizonte estriba en la sentencia délfica "conócete a ti mismo"; aquí se trata de reconocer lo que soy, saberlo) y el comportamiento práctico consigo mismo (estimulado por el apotegma de Píndaro "llega a ser el que eres", se trata de ser quien verdaderamente quiero ser).

Ahora bien, Tugendhat entiende las "cualidades subjetivas relevantes" en términos de "disposiciones" en sentido aristotélico. Dice "[u]na disposición es, según Aristóteles, una capacidad para actuar de cierto modo y que (a su vez) se puede adquirir sólo por actuar de ese modo"24. Por otra parte, aunque Tugendhat distingue cuatro tipos de disposiciones (las técnicas, las que dependen de un colectivo, las que desempeñan un papel y las del carácter), lo que le interesa subrayar es que, lo que tienen en común es que dependen en parte de algo que "ya está ahi", del pasado, pero que ellas mismas son algo prospectivo, y en esta dirección dependen del sujeto. Por ello la frase "yo soy tal y tal" es ambigua por cuanto puede referirse a algo que yo ya soy y también puede referirse a algo que yo libremente quiero ser. Lo que no queda claro es de qué manera se relacionan estas dos dimensiones de la identidad: la del pasado y la del futuro, la del dato y la voluntariamente asumida, el comportarse teórico consigo mismo (donde se pone en juego un saber esencialmente descriptivo) con el comportarse práctico consigo mismo (donde lo que se debate es el bacerme de acuerdo al modelo normativo). Pues, si "el querer nunca se dirige simplemente a algo en el futuro, sino que es ya siempre una respuesta a algo dado" 25 , entonces quedaría por

${ }^{24}$ Ibidem.

25 Ibidem, p. 21. 
mostrarse de qué manera una puede condicionar, determinar, negar, asumir, reformular, etc. a la otra. Si el querer debe referirse a lo que ya soy, es necesario detenerse en el modo en que un sujeto puede aclararse lo que ya es, y cómo puede, a partir de aquí, referirse al futuro. Ya en sus primeros escritos sobre el tema Tugendhat reconocía la misma laguna: "Esto vale finalmente también para un aspecto del comportarse consigo mismo que Habermas acentúa con razón y que yo sólo toqué brevemente en mi interpretación de Heidegger (...) pero que en lo esencial he descuidado, y es el de la continuidad de la propia historia de vida"26. Es este factor de la "ontinuidad de la propia bistoria" el que la identidad narrativa no descuida.

Quisiera ahora mostrar en qué medida la identidad narrativa permite completar la propuesta prescriptivo-normativa desarrollada hasta aquí. Pues, si mi tesis es que la narratividad no es un mero agregado, no es un plus que puede o no estar, sino que es indispensable para el tratamiento de la identidad, entonces hay que señalar lo que la falta de ella implica.

Como había mencionado, hay en Tugendhat una laguna (producida por la ausencia de la dimensión narrativa) en lo que se refiere a la relación entre el orden del dato, que se inscribe dentro del presente y el pasado, y el orden de la acción, del "hacerme"(relativamente libre) cuyo eje temporal es el futuro. Tal vez esto pueda verse mejor si tomamos como centro del análisis su noción de "disposición adquirida". Recordemos que para este autor, la estructura del identificarse-con... hace referencia a la identidad cualitativa, y ésta, a su vez, se fundamenta en la disposición en tanto capacidad de actuar de cierto modo. Así, una cualidad que contribuye a nuestra identidad puede ser puesta como respuesta legítima a la pregunta práctica fundamental.

A esto podemos contraponer, en principio, dos argumentos provenientes de los defensores más relevantes de la "identidad narrativa". El primero es el argumento de Ricoeur. Consiste en relacionar la "disposición adquirida" con el "carácter" y mostrar las implicaciones

26 Tugendhat, E. Autoconcienciay Autodeterminación. México. F.C.E., 1993, p. 227. 
temporales de este par para, finalmente, poner en relación temporalidad y narratividad. Para Ricouer, en efecto, "[e]l carácter (...) designa el conjunto de disposiciones duraderas en las que reconocemos a una persona"27. Así, la idea de disposición (tan importante en los análisis de Tugendhat) es parte de la definición del carácter. La duración, por su parte, cuando se predica de la disposición, hace referencia a un modo de ser "constante", y esta constancia implica un modo fuerte (rígido) de permanencia en el tiempo. Cuando hablamos de disposición adquirida podemos pensar por lo tanto en una cuasi-inmutabilidad. Esto es lo que significa, en este contexto, la palabra "adquirido". Ahora bien, junto con esta cuasiinmutabilidad está la dimensión temporal de la "adquisición". De esta manera: "a la noción de disposición se vincula la de costumbre, con su doble valencia de costumbre que según se dice, estamos contrayendo y de costumbre ya adquirida" 28 .

Aquí emergen los rasgos temporales, pues la costumbre otorga una bistoria al carácter, pero una historia en la que la sedimentación tiende a recubrir, y en el límite, a anular la innovación que, por definición, la ha precedido. Si ponemos el concepto de hábito entre el concepto de disposición adquirida y el de carácter, podremos comprender por qué autores como Ravaisson veían en el carácter "el retorno de la libertad a la naturaleza". El núcleo de inmutabilidad, que posibilita la continuidad ininterrumpida a través del tiempo, está dado por la sedimentación (o cristalización), que hace del carácter el modo privilegiado de la identidadidem. Pero la sedimentación no anula la ipseidad, pues, aunque mi carácter sea, en términos pascalianos, una segunda naturaleza, mi carácter soy "yo", "yo-mismo", “ipse”. Cada hábito así contraído, y convertido en disposición duradera, constituye un signo distintivo por el que se puede identificar y reidentificar a una persona.

Pero el carácter, según Ricoeur, se relaciona también con lo que Tugendhat llama "identidad cualitativa" en el sentido de la estructura "identificarse-con". Con esta estructura ingresa "lo otro" en la

${ }^{27}$ Ricoeur, P., Si mismo como otro, p. 115.

${ }^{28}$ Ibidem. 
composición de "lo mismo": "en gran parte la identidad de una persona, de una comunidad, está hecho de estas identificaciones-con valores, normas, ideales, modelos, héroes, en los que la persona, la comunidad, se reconocen"29.

El identificarse-con..., esencial al carácter, realiza un proceso similar al de sedimentación del que hablaba más arriba. Pero, en este caso, lo que se obtura es el efecto inicial de alteridad que presupone, pues el movimiento va de afuera hacia adentro, dando lugar al proceso de "interiorización" tan bien trabajado por la tópica freudiana. Entonces, sedimentación e interiorización hacen posible la identidad numérica, cualitativa y la continuidad ininterrumpida de una persona.

Sin embargo, agrega Ricouer,

[1]a dialéctica de la innovación y de la sedimentación, subyacente al proceso de identificación, está ahí para recordar que el carácter tiene una historia, diríase contraída, en el doble sentido del termino "contracción": abreviación y afección. Por lo tanto, es comprensible que el polo estable del carácter pueda revestir una dimensión narrativa (...) lo que la sedimentación ha contraído, la narración puede volver a desplegarlo ${ }^{30}$.

Es el aspecto narrativo, pues, el que permite desplegar las causas, circunstancias, motivos, azares, acontecimientos, etc., de la adquisición de una determinada disposición, mostrando su concurrencia sinérgica. Así, la

${ }^{29}$ Ricoeur P., Sí mismo comı otro, p. 116. Esta noción de ipseidad como fidelidad a un ideal o proyecto existencial es adelantado por Ricoeur en un artículo de 1983 llamado "Muere el personalismo, vuelve la persona". Allí la fidelidad se anticipa bajo la figura del compromiso. La persona, como actitud, se define por su orientación a un orden de valores que la convocan. La identidad-ipse puede verse también en este mantenimiento, no ya de la promesa, sino del reconocimiento de aquello que, “...más grande que yo, más durable que yo, más digno que yo, me constituye en deudor insolvente (...), mi puesto me es asignado, la jerarquización de preferencias me obliga" (Ricoeur, P. Amor y Justicia, Madrid, Caparrós, 2000, p. 92).

30 Ricoeur, P., Sí mismo conıo otro, p. 117. 
narratividad es un momento ineludible del comportarse práctico consigo mismo. En este caso es la narración la que arroja luz sobre la estructura del identificarse-con... al mostrar la genealogía de esta estructura en la adquisición de determinadas disposiciones del carácter. Es la dimensión temporal del carácter la que lo colocará en el camino de la narrativización de la identidad personal. La narración destaca el elemento de ipseidad que hay en el carácter. Pues es por intermedio del narrar como se aclaran las circunstancias, causas, deliberaciones, fines, etc., que concurrieron durante todo el proceso de cristalización de una determinada disposición. Si la adquisición tuvo una etapa inicial, una etapa de fijación y una etapa de sedimentación, entonces, ante la necesidad de consentir o negar dicha adquisición, la bistoria de las etapas debe ser relatada. Así,

el entrelazamiento de los motivos subjetivos y razones más generales que explican la decisión requiere para ser expuesta la forma de una narración. Para comprender es necesario un relato a través del cual se despliega una trama en la que los personajes van expresando o poniendo de manifiesto la conexión intrínseca de sus actos y sus motivos $^{31}$.

El segundo argumento es de MacIntyre. Aquí se pone el acento en la peculiaridad de la posible respuesta a la pregunta práctica fundamental. Si la identidad no brota sólo de la pregunta, sino mejor de la respuesta que damos a la pregunta ¿quién quiero ser? (es decir ¿qué y cómo quiero ser?), y si esta respuesta debe abarcar la totalidad de una vida, entonces debemos analizar qué tipo de respuesta pide esta pregunta. Si la respuesta a la pregunta ¿quién quiero ser? debe contener, primero, la respuesta a la pregunta ¿quién soy? (y, por lo tanto, ¿cómo he llegado a ser quien soy?), para luego pasar a la respuesta a la pregunta ¿qué y cómo quicro ser?, entonces debemos encontrar un modo de enlazar las tres dimensiones temporales que se encuentran en cada una de ellas. Según MacIntyre, la única forma que tenemos de dar unidad a las tres respuestas es por intermedio de una

${ }^{31}$ Guariglia, O., Moralidad: Etica Universalista y Sıjeto Moral, Buenos Aires, F.C.E., 1996 , p. 226. 
narración encarnada por una vida única. La pregunta práctica fundamental exige como respuesta una narración.

Una de las categorías principales que ingresa MacIntyre en su argumento es la categoría de "búsqueda". De esta manera, la respuesta a la pregunta por la identidad no puede tener una forma completa y acabada, sino que se erige como algo que hay que "buscar". Dice: "La unidad de la vida humana es la unidad de un relato de búsqueda. Una búsqueda ¿de qué? Sin un concepto parcialmente determinado de telos final no puede haber principio alguno para esa búsqueda" 32 .

Podríamos traducir la identidad cualitativa en términos de "búsqueda del bien", o de "búsqueda de la felicidad". Pero la categoría de "búsqueda" encierra cierta indeterminación, pues "búsqueda" no significa ir detrás de algo que ya está adecuadamente caracterizado. Es en el transcurso mismo de la búsqueda en donde "lo buscado" se entenderá, al fin, como la meta de la propia búsqueda. Por ello MacIntyre apela a la narración como modo en que se esclarece la noción de búsqueda. Es en los relatos (sean ficticios o no) en donde hace su epifanía lo que significa para el hombre buscar su propia identidad.

La identidad cualitativa necesita de la dimensión narrativa. En este contexto, Habermas afirma:

Sólo quien toma a su cargo su propia vida responsabilizándose de ella puede ver en ella la realización de sí-mismo. Hacerse cargo de la propia vida responsabilizándose de ella significa tener claro quién quiere uno ser, y, desde este horizonte, considerar las huellas de las propias interacciones como si fueran sedimentos de las acciones de un autor dueño de sus actos ${ }^{33}$.

Este "tomar a nuestro cargo" es un requisito esencial de la autodeterminación. Es interesante mostrar que aquí, Habermas y

32 MacIntyre, A., Tras la virtud, Barcelona, Crítica, 2001, p. 270.

${ }^{33}$ Habermas, J., Teoría de la acción comunicativa II, Madrid, Taurus, 1999, p. 142. 
MacIntyre coinciden. La identidad personal estriba en la capacidad que tiene un agente de responsabilizarse por su propia vida. Ahora bien, esta capacidad de asumir la propia biografía implica lógicamente una fase narrativa.

la práctica narrativa (...) cumple también una función para la autocomprensión de las personas que han de objetivar su pertenencia al mundo de la vida de que son miembros en su rol actual de participantes en la comunicación, ya que sólo podrán desarrollar una identidad personal si se dan cuenta de que la secuencia de sus propias acciones constituye una vida susceptible de narrarse, y sólo podrán desarrollar una identidad social si se dan cuenta de que a través de su participación en las interacciones mantienen su pertenencia a los grupos sociales y de que con esa pertenencia se hallan involucrados en la historia narrativamente exponible de los colectivos $^{34}$.

Como dijimos anteriormente, el relato tiene la virtud de conjugar dos elementos constitutivos de la identidad: "lo que hacemos" y "lo que nos pasa". Según el primero, el sujeto es artífice de su propia identidad; según el segundo, el sujeto es receptivo de su identidad. Conforme el mapa que venimos trazando, "lo que hacemos" es objeto de las teorías "normativo-prescriptivas", mientras que "lo que nos pasa", es objeto de las teorías descriptivas. La identidad narrativa, tal como es elaborada por Ricoeur y MacIntyre, logra conjugar ambas dimensiones. La construcción de una "trama" implica un proceso integrador de elementos heterogéneos, v.g incidentes múltiples y unidad de la historia, circunstancias deseadas y no-deseadas, agentes y pacientes, encuentros buscados y fortuitos, etc. $\mathrm{Al}$ reunir elementos dispares, la narración ofrece un modelo de inteligibilidad único. Lo que da unidad e identidad a estos elementos es la narración misma, por ello decíamos anteriormente que la identidad del personaje se deriva de la identidad dinámica de la historia ${ }^{35}$. Por ello sostengo que la

34 Ibidem, p. 194.

${ }^{35}$ Cfr. Ricoeur, P., Educación y Politica, Buenos Aires, Docencia, 1989, pp. 46-50. 
narratividad no es algo que podamos saltar o esquivar al momento de preguntar ¿quién soy?

Pero lo interesante del argumento es que también la dimensión prescriptiva requiere de la narración so pena de verse reducida al sinsentido. Una acción se hace inteligible, y por lo tanto puede formar parte de la identidad, sólo si puede ser remitida a totalidades más amplias dentro de las cuales aquélla adquiere significado. La pregunta ¿qué hace él?, realizada en el vacío, puede dar lugar a una gran cantidad de respuestas todas ellas igualmente verdaderas: hace un pozo, planta una semilla, busca distraerse de sus preocupaciones, trata de satisfacer a su mujer, practica la jardinería, intenta demostrar una hipótesis filosófica, etc. Lo único que nos permite integrar estas respuestas dándoles unidad e inteligibilidad es por medio de una narración. Por lo tanto, la acción es inteligible sólo si es previamente narrada. Ahora bien, MacIntyre agrega que las respuestas que damos a la pregunta ¿qué hace él? deben tener en cuenta las intenciones del agente. Estas intenciones se ordenan, conforme al intervalo temporal en que se llevan a cabo, jerárquicamente en "intenciones inmediatas", "intenciones mediatas", "intenciones a largo plazo" e "intenciones a muy largo plazo". Entonces, las intenciones inmediatas sólo se tornan significativas por referencias a las intenciones mediatas; éstas, a su vez, si se remiten a las intenciones a largo y muy largo plazo: "De ahí que la conducta sólo se caracterice correctamente cuando sabemos qué intenciones a largo y muy largo plazo se invocan, y cómo las intenciones a corto plazo se relacionan con aquellas. Una vez más nos vemos implicados en una narrativa"36.

Si la identidad se conforma, pues, al menos en parte, por lo que "Jacemos"; y si lo que bacemos resulta inteligible dentro de una bistoria narrada, entonces la identidad y la narratividad se unen ineluctablemente. La narratividad, decíamos, tiene la capacidad de conjugar "lo que hacemos y lo que nos pasa". Ella logra combinar, en una historia única y completa, los aspectos normativos, y los aspectos "pasivos".

${ }^{36}$ MacIntyre, A., Tras la virtud, p. 256. 
Lo que he llamado una historia es una narración dramática representada, en la que los personajes son también autores. Por supuesto que los personajes nunca salen literalmente ab initio, se lanzan in medias res, ya realizados los principios de sus historias por aquello y por quienes vinieron antes. La diferencia entre los personajes imaginarios y los reales no reside en la forma narrativa dentro de la cual actúan, está en el grado de su autoría ${ }^{37}$.

Aquí encontramos nuevamente la paradoja exhibida por Tugendhat. Nuestra identidad pareciera estar bajo nuestra potestad, aunque nuestra potestad se ejerce sobre algo "dado", "recibido". En la bistoria narrada se muestra de qué manera se conjuga esta mezcla de posesión y desposeimiento de la identidad personal. Según MacIntyre, la imprevisibilidad coexiste con el carácter teleológico de la vida, sin que se perciba en ello ninguna contradicción. Esta coexistencia se ve en la narración de aquella historia en la que nosotros somos el personaje principal.

Pero el relato agrega otra dimensión a la búsqueda. Me refiero a la dimensión del "acontecimiento" elaborado por Hannah Arendt. La respuesta a la pregunta ¿quién soy? debe poder incorporar aquellos acontecimientos que nos han ido modificando "cualitativamente" a lo largo de nuestra vida. La noción de "acontecimiento" hace referencia a la "ruptura" de cierto encadenamiento de sucesos, de acciones por la aparición de una "novedad" que modifica radicalmente la sucesión de los hechos. La respuesta a la pregunta ¿quién quiero ser? puede experimentar profundos virajes. Estos cambios cualitativos son producto de los "imprevistos" que componen nuestra vida, y por lo tanto, deben ser incorporados en la narración que estamos llamados a hacer de nosotros mismos ${ }^{38}$.

${ }^{37}$ Ibidem, p. 265.

38 " $[\mathrm{L}]$ a narrativa en todas sus formas es una dialéctica entre lo que se esperaba y lo que sucedió. Para que exista un relato hace falta que suceda algo imprevisto; de otro modo 'no hay historia'." (Bruner, J., La fábrica de historias, Buenos Aires, F.C.E, 2003, p. 31). 
El poeta, en un sentido muy general, y el historiador, en un sentido especial, tienen la tarea de poner este proceso de narración en movimiento y de involucrarnos en él. Y nosotros, aunque no somos en la mayoría de los casos, ni poetas ni historiadores, estamos familiarizados con la naturaleza de este proceso por nuestra propia experiencia de vida, pues también nosotros tenemos la necesidad de recordar los sucesos significativos de nuestras vidas narrándolos a nosotros mismos y a otras personas ${ }^{39}$.

Por ello, no todo está del lado de la autoría. Existen circunstancias no elegidas que provocan un replanteamiento general de la pregunta práctica fundamental. La tesis de Arendt es que estos "acontecimientos" que provocan una fractura en el continuum temporal, sólo adquieren su verdadero estatuto para la identidad si los incorporamos en una narración. Dice, "[a]contecimiento es lo que sobreviene o adviene en el tiempo (...) humano (...). El acontecimiento es lo que para los individuos como para las colectividades emerge a título de singular imprevisto en el tiempo, aparece en el tiempo notoriamente y merece ser conmemorado como tal" ${ }^{40}$. Si la respuesta a la pregunta ¿quién quiero ser? puede tener como causa algún acontecimiento, entonces la forma de bacerla inteligible para el sujeto portador de identidad es narrando ell acontecimiento/s que dieron lugar a la nueva respuesta a la pregunta ¿quién soy?

\section{Conclusión}

El trabajo ha adoptado una forma programática. He querido mostrar la necesidad de repensar algunos argumentos de la teoría descriptivo-reduccionista a la luz del concepto de identidad narrativa. Así, del lado de las teorías no-reduccionistas de ascendencia egológicocartesiana, emerge otra teoría no-reduccionista de ascendencia hermenéutica. La tarea del reduccionismo consiste ahora no en refutar aquella, sino ésta, pues es la que, en la actualidad, presenta mejores argumentos.

39) Arendt, H., Hombres en tiempos de oscuridad, Barcelona, Gedisa, 2001, p. 323.

${ }^{40}$ Arendt, H., La condición bumana, Barcelona, Paidós, 1998, p. 133. 
Luego he querido mostrar la necesidad de completar las teorías prescriptivas (en particular la de Tugendhat) con el mismo concepto, más abarcativo, de identidad narrativa. En efecto, la narratividad se ha erigido en momento ineludible de la comprensión de sí, y ha mostrado poder conjugar en un movimiento dialéctico todas las variables que deben ingresar en la respuesta a la pregunta ¿quién soy?, en su doble forma: ¿cómo he llegado a ser quién soy?, y ¿quién quiero ser de ahora en más? La narratividad no sólo logra engarzar el pasado y el futuro, sino que a su vez, logra armonizar pasividad y actividad (pasividad hacia atrás y actividad hacia delante). Por último, la identidad narrativa ha podido incorporar el elemento de "imprevisibilidad" que forma parte constitutiva de la identidad. La noción de acontecimiento, tomada de Arendt, es esencial en la respuesta a la pregunta ¿quién soy?, pero, el acontecimiento en tanto efecto de quiebre sólo adquiere sentido dentro del relato de la propia vida.

Para terminar, soy consciente de todos los problemas que encierra el concepto de narratividad cuando se vuelca sobre la cuestión de la identidad. Pero no ha sido el objetivo de este trabajo analizar la estructura de la narración. Ese análisis sólo se mostrará pertinente cuando nos hayamos convencido de que la narración es un momento esencial de la constitución de la identidad personal.

Recibido: 10/2010; aceptado: 2/2011. 